\title{
Survival benefit of hepatic resection versus transarterial chemoembolization for hepatocellular carcinoma with portal vein tumor thrombus: a systematic review and meta-analysis
}

Xiu-Ping Zhang ${ }^{1 \dagger}$, Kang Wang ${ }^{1 \dagger}$, Nan $\mathrm{Li}^{1 \dagger}$, Cheng-Qian Zhong ${ }^{1}$, Xu-Biao Wei ${ }^{1}$, Yu-Qiang Cheng ${ }^{1}$, Yu-Zhen Gao ${ }^{2}$, Han Wang ${ }^{3}$ and Shu-Qun Cheng ${ }^{1 *}$

\begin{abstract}
Background: No consensus treatment has been reached for hepatocellular carcinoma (HCC) with portal vein tumor thrombus (PVTT). Hepatic resection (HR) and transarterial chemoembolization (TACE) have been recommended as effective options, but which is better remains unclear. This meta-analysis is to compare the effectiveness of HR and TACE for HCC with PVIT patients.

Methods: The PubMed, EMBASE, Cochrane Library, VIP, Wan Fang, and Sino Med databases were systematically searched for comparing HR and TACE treating PVTT.

Results: Twelve retrospective studies with 3129 patients were included. A meta-analysis of 11 studies suggested that the 1-, 2-, 3-, and 5-year overall survival (OS) rates $\left(\mathrm{OR}=0.48,95 \% \mathrm{Cl}=0.41-0.57, \mathrm{I}^{2}=37 \%, P<0.00001 ; \mathrm{OR}=0.21,95 \%\right.$ $\mathrm{Cl}=0.12-0.38, \mathrm{I}^{2}=43 \%, P<0.00001 ; \mathrm{OR}=0.35,95 \% \mathrm{Cl}=0.28-0.44, \mathrm{I}^{2}=53 \%, P<0.00001 ; \mathrm{OR}=0.28,95 \% \mathrm{Cl}=0.14-0.54$, $P^{2}=72 \%, P=0.0001$, respectively) favored HR over TACE. In a subgroup analysis, HR had better 1-, 2-,3, 5-year OS for type I PVIT $\left(\mathrm{OR}=0.33,95 \% \mathrm{Cl}=0.17-0.64, \mathrm{I}^{2}=20 \%, P=0.001 ; \mathrm{OR}=0.32,95 \% \mathrm{Cl}=0.16-0.63, \mathrm{I}=0 \%, P=0.001 ; \mathrm{OR}=0.18,95 \%\right.$ $\mathrm{Cl}=0.09-0.36, \mathrm{I} 2=0 \%, P<0.00001 ; \mathrm{OR}=0.07,95 \% \mathrm{Cl}=0.01-0.32, \mathrm{I} 2=0 \%, P=0.0006$, respectively) and better $1-, 3-$, and 5-year OS for type II PVTT $\left(\mathrm{OR}=0.37,95 \% \mathrm{Cl}=0.20-0.70, I^{2}=59 \%, P=0.002 ; \mathrm{OR}=0.22,95 \% \mathrm{Cl}=0.13-0.39, I^{2}=0 \%\right.$, $P<0.00001 ; \mathrm{OR}=0.16 ; 95 \% \mathrm{Cl}=0.03-0.91 ; I^{2}=51 \%, P=0.04$, respectively). There was no difference in 1-, 3-, or 5-year OS between HR and TACE for type III PVTT $\left(\mathrm{OR}=0.86,95 \% \mathrm{Cl}=0.61-1.21, \mathrm{I}^{2}=0 \%, P=0.39 ; \mathrm{OR}=0.83,95 \% \mathrm{Cl}=0.42-1.64\right.$, $\mathrm{I}^{2}=0 \%, P=0.59 ; \mathrm{OR}=0.59,95 \% \mathrm{Cl}=0.06--6.04, \mathrm{I}^{2}=65 \%, P=0.66$, respectively).
\end{abstract}

Conclusions: HR may lead to longer OS for some selected HCC patients with PVTT than TACE, especially for type I or II PVIT, with less difference being observed for type III or IV PVTT.

Keywords: Hepatic resection, Transarterial chemoembolization, Hepatocellular carcinoma, Portal vein tumor thrombus

\footnotetext{
* Correspondence: chengshuqun@aliyun.com

${ }^{\dagger}$ Equal contributors

'Department of Hepatic Surgery VI, Eastern Hepatobiliary Surgery Hospital,

Second Military Medical University, 225 Changhai Road, Shanghai 200433,

China

Full list of author information is available at the end of the article
} 


\section{Background}

Hepatocellular carcinoma (HCC) is one of the most common types of cancer and has dismal outcomes with high morbidity and mortality [1]. Portal vein tumor thrombosis (PVTT) is a commonly recognized independent risk factor for $\mathrm{HCC}$ prognosis, occurring in $44-62.2 \%$ of these patients and being associated with a natural median survival time (MST) of 2.7-4 months [2] without any treatment interventions. According to Barcelona Clinic Liver Cancer (BCLC) guidelines [3], sorafenib is the only recommended treatment for PVTT, and the reported median survival time (MST) of patients treated with sorafenib is as short as 10.7 months [4]. However, multimodal treatments, such as hepatic resection (HR) and transarterial chemoembolization (TACE), have been widely applied to PVTT and have shown a survival benefit in patients with $\mathrm{HCC}$ in Asian countries [5-7]. At present, treatment strategies for HCC patients with PVTT remain controversial.

Due to recent advances in perioperative management and surgical techniques, HR has become a reasonably safe treatment option. Aggressive HR for HCC with PVTT has been proposed by several tertiary centers $[6,8,9]$. Similarly, TACE provides favorable long-term survival outcomes in advanced HCC patients with PVTT compared with the best supportive treatments if they have adequate liver function [7, 10]. However, the number of patients enrolled in these studies has generally been small, and the reports suffer from substantial selection bias. Therefore, whether to select HR or TACE as an initial treatment for these patients remains unclear [11-13]. Unfortunately, there is no reported systematic review or meta-analysis on the above controversy.

Here, we present the first systematic review and metaanalysis comparing HR and TACE for HCC with PVTT, with a focus on different types of PVTT.

\section{Methods}

\section{Search strategy}

Following the Preferred Reporting Items for Systematic Reviews and Meta-Analyses (PRISMA) guidelines [14], we systematically searched the PubMed, Cochrane Library, EMBASE, Web of Science, Chinese National Knowledge Infrastructure (CNKI), VIP, Wan Fang, and Sino Med databases with no limitations on language. Meanwhile, we comprehensively searched ClinicalTrials.gov to attain available outcomes of ongoing studies comparing HR with TACE for PVTT. The search was updated on January 1, 2017. The following search terms were used: "liver surgery" or "hepatic resection" or "surgical resection" AND "transcatheter arterial chemoembolization" or "TA $(C) E$ " or "transarterial chemoembolization" or "chemoemboli*" or "emboli*" AND "(liver or hepatic or hepatocellular or hepatocellular) and (carcinom* OR cancer OR neoplasm* OR malign* OR tumor* OR tumour*)" or "HCC" or "hepatoma*" AND "portal vein tumor thrombus" or "(portal vein thrombosis)" or "PVTT". All abstracts were independently screened by Zhang XP and Wang K, and full-text reports of the included papers were obtained for another screen.

\section{Study selection Inclusion criteria}

This meta-analysis was focused on comparing the efficacy and safety of HR versus TACE in the treatment of HCC patients with PVTT. Therefore, only comparative analysis concerning clinical value of $\mathrm{HR}$ alone versus TACE alone for HCC patients with PVTT was used. The inclusion criteria should be: (1) HCC patients with various types of PVTT who underwent HR or TACE without other treatments. (2) Clinical trials comparing the therapeutic effect of HR with TACE for these patients. (3) Trials including original data, such as 6month or 1,2,3,5-years' overall survival (OS), (DFS) and odds ratios (OR) or hazard ratio estimates (HRs) with 95\% confidence intervals (95\% CIs). (3) Relevant degree papers, conference summaries and abstracts, and some ongoing randomized controlled trials (RCTs) about HR or TACE for PVTT, with no publication language limitation applied.

\section{Exclusion criteria}

The exclusion criteria should be: (1) Advanced HCC patients without PVTT. (2) These patients receiving other treatments or combined treatments instead of HR or TACE alone. (3) Narrative reviews, case reports, current affairs review, letters, comments, or studies unrelated to our topics. (4) Repeated papers or papers that did not provide the necessary information.

\section{Data extraction and quality assessment}

Two authors (Zhang XP and Wang K) of this article independently extracted and checked all data from the included papers. If necessary, a third author ( $\mathrm{Li} \mathrm{N}$ ) was invited to participate in resolving disagreements through discussion and consensus. The following data were extracted:

1. Basic data from the article, including country, study design, authors, patient characteristics, methods and procedures of TACE or HR.

2. Basic data from patients with $\mathrm{HCC}$, including therapy outcomes for HCC with PVTT, and the outcomes of patients undergoing HR or TACE for various PVTT types.

Some data were calculated, such as study methods and OS outcomes in different years, recurrence rate and 
DFS, some measures related to different PVTT subgroups, and OR estimates with 95\% CIs.

Three authors of this article together extracted the data with a consensus and then entered the requisite data into RevMan software, version 5.3 (The Cochrane Collaboration, http://tech.cochrane.org). For nonrandomized controlled trials (NRCTs), the quality of the studies included in the meta-analysis was assessed using the Newcastle-Ottawa Scale (NOS) (The Ottawa Hospital: Research Institute. 2009. Available from URL: http://www.ohri.ca/programs/clinica1_epidemiology/oxford.asp). In the NOS, if the quality score of an article is greater than or equal to 6 with a full score of 9, then the article is considered to be high quality. Publication bias was assessed with funnel plots, Begg's test and Egger's test [15], with a $P$-value $<0.05$ judged as statistically significant. All metaanalyses had good reliability and were not influenced by any one of the included studies based on calculations using RevMan software, version 5.3.

\section{Statistical analysis}

The outcomes included OS rate, DFS, and outcomes of different types of PVTT. The included data are presented as OR estimates with 95\% CIs for all outcomes. OS rates were assessed for different years, with some data being obtained from survival curves. The RRs of each study were pooled using a fixed effects model or a random effects model with RevMan version 5.3.

According to the suggestions of the Cochrane collaboration, Q statistics and the I2 index were used to assess heterogeneity, with significant heterogeneity indicated at $P<0.05$ and an $\mathrm{I} 2$-index $>50 \%$ [16]. The estimates were pooled with a fixed effects model if no significant heterogeneity was identified, whereas a random effects model was used for estimates with heterogeneity. Subgroup analyses were performed according to PVTT type.

\section{Results}

\section{Identification of eligible studies}

Using our search strategy, we identified 1200 relevant studies, of which 1112 duplicates were excluded. Another 70 articles were excluded after the titles and abstracts were reviewed. Six studies were excluded for not meeting the requirements, such as the use of additional therapies and a lack of basic data, as shown in Fig. 1. At last, 12 retrospective controlled studies [11-13, 17-25] meeting the inclusion standards and involving 3129 patients were eligible for inclusion in the systematic review. The meta-analysis assessed 11 of these articles because one article had an overlapping patient cohort from 1997 to 2000 .

\section{Patient characteristics}

Table 1 presents the baseline characteristics of the patients in the included studies. The 12 studies were published from 2001 to 2016. A total of 3129 HCC patients with PVTT were included, of whom 1483 received HR and 1646 received TACE as an initial treatment. More men than women with HCC and PVTT were included in the analysis. Tumor size mostly ranged from 5 to $10 \mathrm{~cm}$. Most tumors were single. Type I and II PVTT were most common and were determined using Cheng's Classification [26, 27]. The baseline liver function for most participants was Child-Pugh A or B. Ten studies reported mostly HBV virology for $\mathrm{HCC}$ patients [11-13, 17-19, 22-25]. Serum AFP, a diagnostic marker of $\mathrm{HCC}$, was more than $400 \mathrm{mg} / \mathrm{L}$ in 10 studies [11-13, 17-19, 22-25]. Specific details of the patients' characteristics are recorded in Table 1.

\section{Treatment regimens}

HR and TACE were performed on patients in two groups. The description of the operative procedure for HCC with PVTT was the same in all included studies. En bloc resection, partial hepatectomy or hemihepatectomy could be performed in type I/II PVTT patients because the PVTT in these cases did not invade the edge of the resection range and was confined to the hepatic lobes or segments. If PVTT had extended to the main portal vein, considered type III PVTT, then hemihepatectomy combined with thrombectomy or main portal vein resection followed by reconstruction is recommended. For example, PVTT can be extracted out from the opened stump of the portal vein and the stump closed after flushing with blood flow and normal saline, confirming that no PVTT remains.

TACE was performed using Seldinger's technique in all included patients. The number of TACE treatment cycles ranged from 1 to 7 . The mean intermediate interval ranged from 4 to 8 weeks. The chemotherapeutic agents were varied among the included studies and included 5-fluorouracil (5-Fu), mitomycin (MMC), cisplatin, carboplatinum and epiadriamycin. Lipiodol and gelatin sponge (Gelfoam) was used as an embolic agent in all studies. None of the patients received other treatments, as shown in Table 2.

\section{Overall survival}

For all included $3129 \mathrm{HCC}$ patients, the median OS ranged from 8 to 64 months in the HR group and from 5 to 32 months in the TACE group as reported in 10 studies [12, 13, 17-22, 24, 25] (Table 3). In the HR group, the 0.5 -year OS rate varied from 45.9 to $46.8 \%$ but was reported in only 2 studies $[19,21]$. The 1-year OS rate varied from 14.2 to $86.5 \%$, the 2 -year OS rate varied from 0 to $58.3 \%$, the 3 -year OS rate varied from 0 


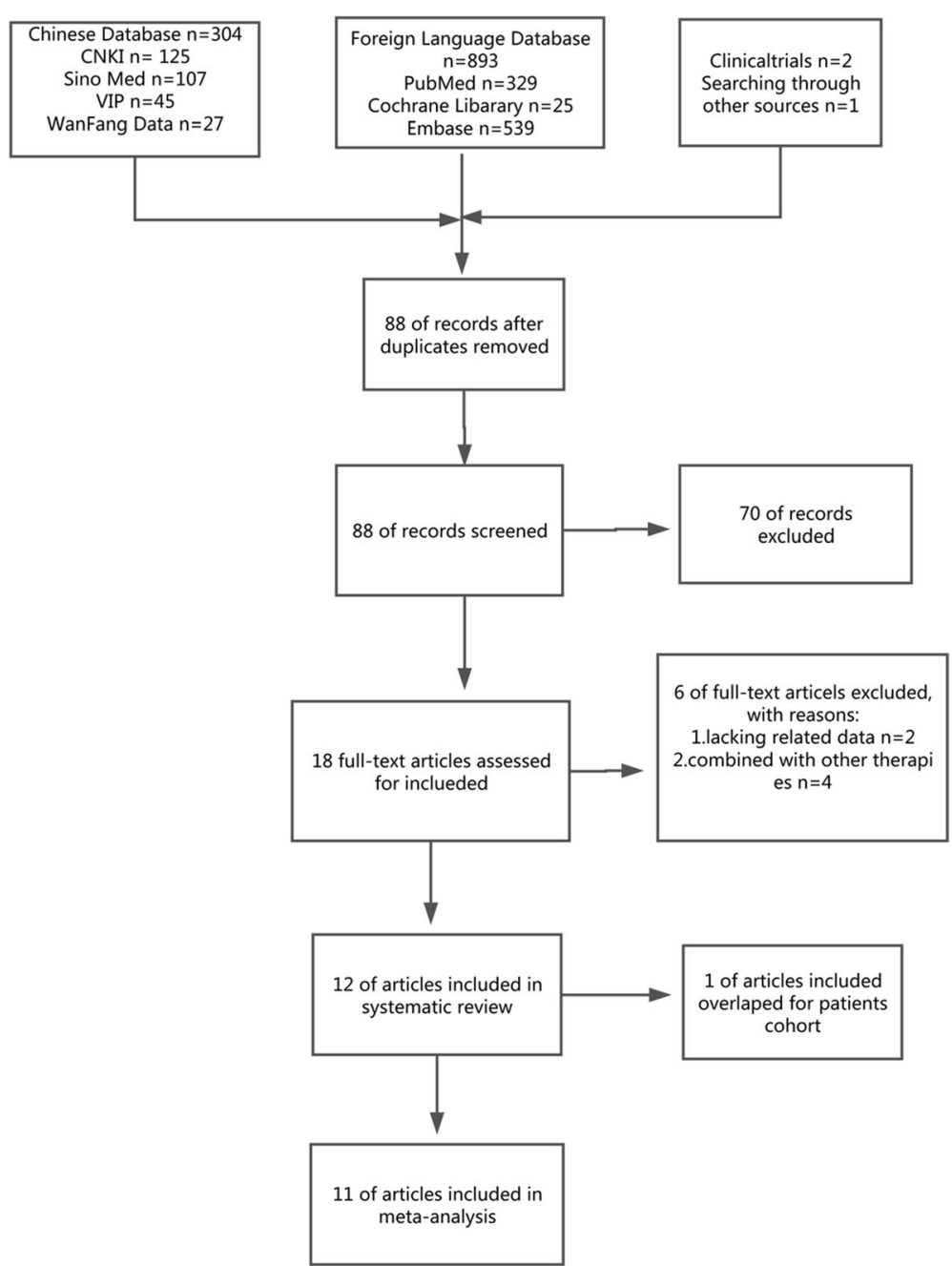

Fig. 1 PRISMA flow diagram of the process used to identify eligible studies. CNKI: Chinese National Knowledge Infrastructure; VIP: Chongqing VIP Database for Chinese Technical Periodicals; Wan Fang: Wan Fang Database; Sino Med: Chinese Biological Medical Literature Database

to $69 \%$, and the 5 -year OS rate varied from 0 to $69 \%$. In the TACE group, the 0.5 -year OS rate ranged from 34.2 to $34.6 \%$, the 1 -year OS rate ranged from 10.5 to $77.6 \%$, the 2-year OS rate ranged from 0 to $17.4 \%$, the 3 -year OS rate ranged from 0 to $50 \%$, and the 5 -year OS rate ranged from 0 to $35 \%$. Based on the preliminary data described above, the 0.5-, 1-, 2-, 3-, and 5-year OS rates were better for the patients receiving HR than those receiving TACE.

Eleven studies were included in the meta-analysis of 1, 2-, 3-, and 5-year OS rates and the corresponding ORs. As shown in Fig. 2, the 1-year OS rates favored HR rather than TACE $(\mathrm{OR}=0.48,95 \% \mathrm{CI}=0.41-0.57, \mathrm{I} 2=$ $37 \%, P<0.00001$; Fig. 2a) in all included studies, with 1464 patients undergoing HR and 1605 patients undergoing TACE. The 2 -year $\mathrm{OS}$ rates $(\mathrm{OR}=0.21,95 \% \mathrm{CI}=$ $0.12-0.38, \mathrm{I} 2=43 \%, \mathrm{P}<0.00001$; Fig. $2 \mathrm{~b})$ were reported in 5 studies with 940 patients undergoing HR and 895 patients undergoing TACE. The 3-year $\mathrm{OS}$ rates $(\mathrm{OR}=$ $0.35,95 \% \mathrm{CI}=0.28-0.44, \mathrm{I} 2=53 \%, \mathrm{P}<0.00001$; Fig. $2 \mathrm{c}$ ) were reported in 10 studies with 1457 patients undergoing HR and 1567 patients undergoing TACE. The 5-year $\mathrm{OS}$ rates $(\mathrm{OR}=0.28,95 \% \mathrm{CI}=0.14-0.54, \mathrm{I} 2=72 \%, P=$ 0.0001 ; Fig. 2d) were reported in 5 studies with 1224 patients undergoing HR groups and 1266 patients undergoing TACE. As shown in Fig. 2, the meta-analysis of RRs for OS indicated that the HCC patients with PVTT who underwent HR had significantly longer survival than those who underwent TACE.

\section{Subgroup analysis for outcomes of different types of PVTT}

Our subgroup analysis uniformly used Cheng's classification (Type I: tumor thrombus involving segmental branches of the portal vein or above; Type II: tumor thrombus involving the right/left portal vein; Type III: 


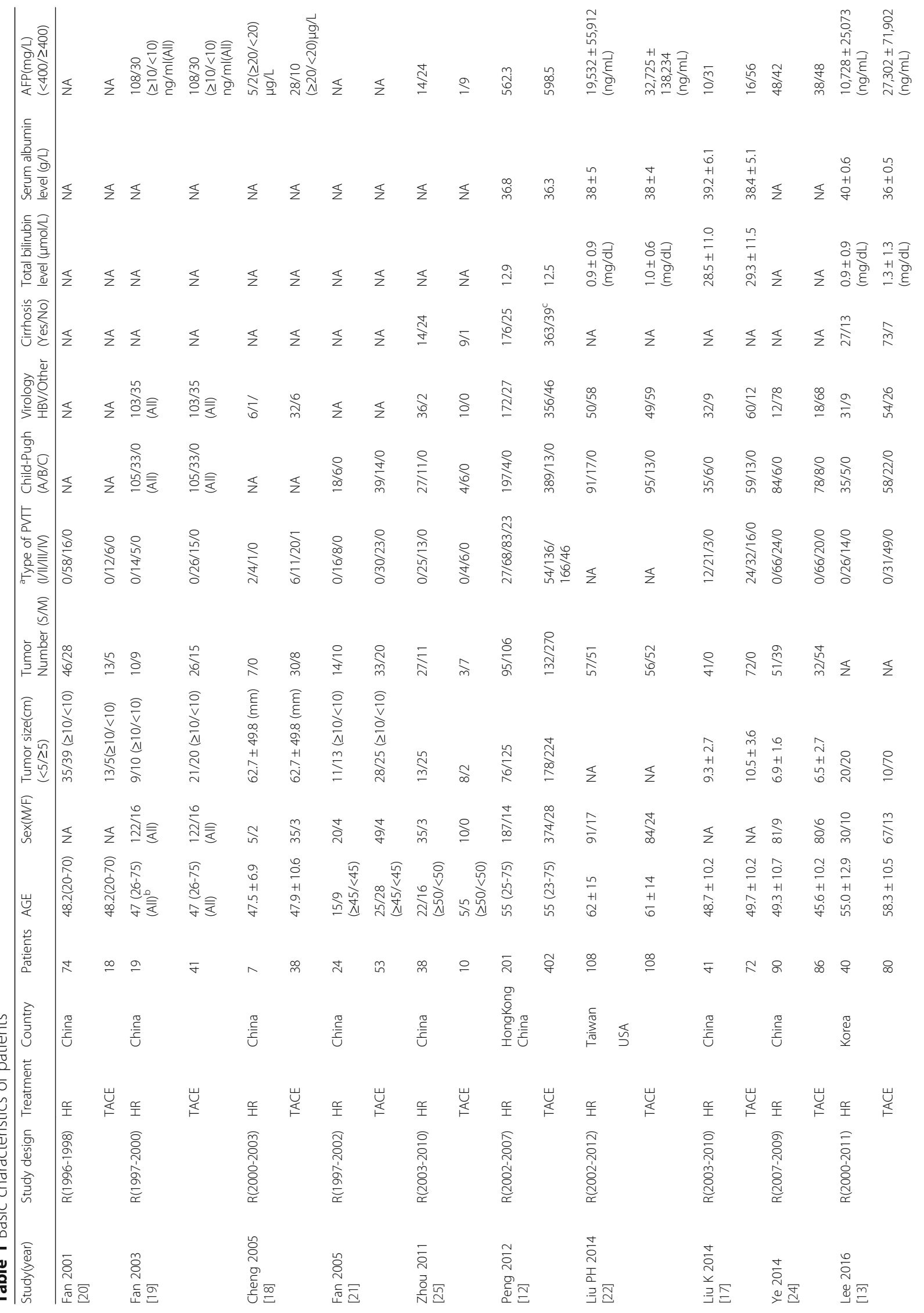




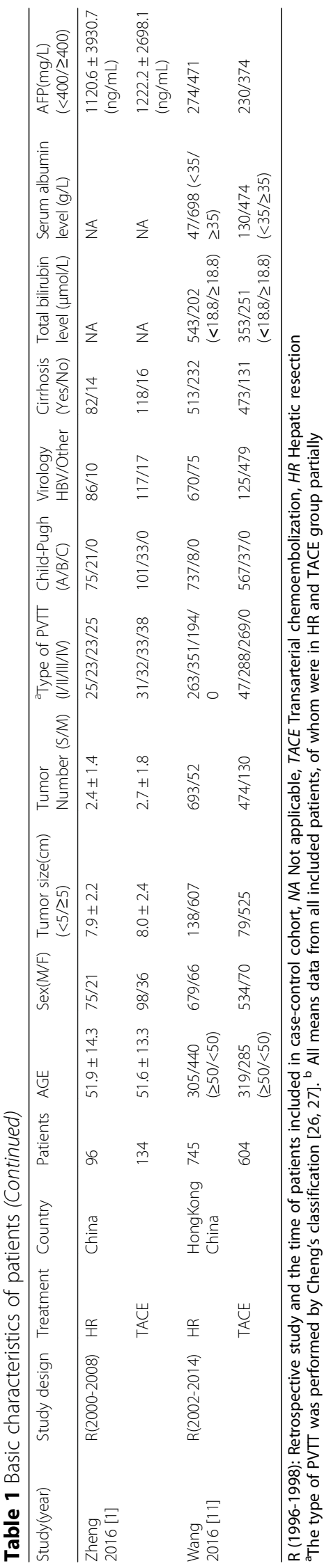


Table 2 Procedures of HR or TACE groups

\begin{tabular}{|c|c|c|c|c|}
\hline \multirow[t]{2}{*}{ Study } & \multirow[b]{2}{*}{ Duration and interval } & \multicolumn{2}{|l|}{ TACE } & \multirow{2}{*}{$\begin{array}{l}\text { HR } \\
\text { Methods and procedure }\end{array}$} \\
\hline & & Chemotherapeutic agents & Embolic agents & \\
\hline Fan 2001 [20] & Median 2 times (ranged 1-4) & $\begin{array}{l}\text { 5-fluorouracil (5-Fu) } 1000 \mathrm{mg}, \\
\text { mitomycin (MMC) } 12 \text { to } 20 \mathrm{mg}, \\
\text { cisplatin or carborplatinum } 80 \mathrm{mg}\end{array}$ & Lipiodol $20 \mathrm{ml}$ & $\begin{array}{l}\text { En-bloc resection, partial hepatectomy } \\
\text { or hemihepatectomy } \\
\text { Thrombectomy }\end{array}$ \\
\hline Fan 2003 [19] & Median 2-3 times (ranged 1-7) & $\begin{array}{l}\text { 5-fluorouracil (5-Fu) } 1000-1500 \mathrm{mg} \text {, } \\
\text { cisplatin } 80-100 \mathrm{mg} \text {, } \\
\text { mitomycin (MMC) } 8 \text { to } 20 \mathrm{mg} \\
\text { or doxorubicin } 80 \mathrm{mg}\end{array}$ & Lipiodol 2-20 ml & $\begin{array}{l}\text { En-bloc resection, partial hepatectomy } \\
\text { or hemihepatectomy Thrombectomy }\end{array}$ \\
\hline Cheng 2005 [18] & NA & Cisplatin, doxorubicin and mitomycin & Lipiodol & $\begin{array}{l}\text { En-bloc resection, partial hepatectomy } \\
\text { or hemihepatectomy Thrombectomy }\end{array}$ \\
\hline Fan 2005 [21] & Ranged $1-7$ times & $\begin{array}{l}\text { 5-fluorouracil (5-Fu) } 1000-1500 \mathrm{mg} \text {, } \\
\text { cisplatin } 80-100 \mathrm{mg} \text {, mitomycin } \\
\text { (MMC) 8-20 mg or epiadriamycin } \\
40-60 \mathrm{mg}\end{array}$ & Lipiodol 5-20 ml & $\begin{array}{l}\text { En-bloc resection, partial hepatectomy } \\
\text { or hemihepatectomy Thrombectomy }\end{array}$ \\
\hline Zhou 2011 [25] & Every $1-2$ months for $2-5$ cycles. & $\begin{array}{l}\text { 5-fluorouracil }\left(500 \mathrm{mg} / \mathrm{m}^{2}\right) \text { and } \\
\text { Adriamycin }\left(30 \mathrm{mg} / \mathrm{m}^{2}\right)\end{array}$ & Gelatin sponge particles $\left(1 \mathrm{~mm}^{3}\right)$ & Hepatectomy plus thrombectomy \\
\hline Peng 2012 [12] & Mean of 2.1 (ranged 1-5) & $\begin{array}{l}\text { Carboplatin } 300 \mathrm{mg} \text {, } \\
\text { epirubicin } 50 \mathrm{mg} \text { and mitomycin } \\
\text { C } 8 \mathrm{mg}\end{array}$ & $\begin{array}{l}\text { Gelatin sponge particles } \\
\text { (1 to } 2 \mathrm{~mm} \text { in diameter) } \\
\text { Lipiodol } 5 \mathrm{~mL}\end{array}$ & Hepatectomy plus thrombectomy \\
\hline Liu PH 2014 [22] & NA & Adriamycin 20-30 mg & $\begin{array}{l}\text { Lipiodol 5-10 ml } \\
\text { Gelfoam (2-3-mm strips) }\end{array}$ & $\begin{array}{l}\text { En-bloc resection, partial hepatectomy } \\
\text { or hemihepatectomy Thrombectomy }\end{array}$ \\
\hline Liu K 2014 [17] & NA & $\begin{array}{l}\text { Cisplatin } 50-100 \mathrm{mg} \text { and epirubicin } \\
20-40 \mathrm{mg}\end{array}$ & Lipiodol 5-20 ml & $\begin{array}{l}\text { En-bloc resection, partial hepatectomy } \\
\text { or hemihepatectomy Thrombectomy }\end{array}$ \\
\hline Ye 2014 [24] & 1 month intervals (ranged $1-7$ ) & $\begin{array}{l}\text { Doxorubicin } 30-50 \mathrm{mg} \text { and } \\
\text { cisplatinum } 50-100 \mathrm{mg}\end{array}$ & $\begin{array}{l}\text { Lipiodol } 10-20 \mathrm{ml} \text { and } \\
\text { gelfoam particles }\end{array}$ & $\begin{array}{l}\text { En-bloc resection, partial hepatectomy } \\
\text { or hemihepatectomy Thrombectomy }\end{array}$ \\
\hline Lee 2016 [13] & Every 4 weeks & Doxorubicin $50 \mathrm{mg}$ & Lipiodol & Hepatectomy plus thrombectomy \\
\hline Zheng 2016 [1] & Mean of 2.9 (ranged $1-7)$ & NA & Gelatin sponge & Hepatectomy plus thrombectomy \\
\hline Wang 2016 [11] & Intervals of 6 to 8 weeks & $\begin{array}{l}\text { Doxorubicin hydrochloride } \\
20-60 \mathrm{mg} \text {, and cisplatin } 5 \mathrm{mg}\end{array}$ & $\begin{array}{l}\text { Lipiodol } 5-30 \mathrm{ml} \text { and } \\
\text { gelfoam fragments }\end{array}$ & $\begin{array}{l}\text { En-bloc resection, partial hepatectomy } \\
\text { or hemihepatectomy Thrombectomy }\end{array}$ \\
\hline
\end{tabular}

Table 3 Outcomes of therapy for HCC with PVIT

\begin{tabular}{|c|c|c|c|c|c|c|c|c|}
\hline Study(year) & Treatments & Patients & Median OS(months) & 6-month(\%) & 1-year(\%) & 2-year(\%) & 3-year(\%) & $\begin{array}{l}5 \text {-year }(\%) \text { of } \\
\text { Survival rates }\end{array}$ \\
\hline \multirow[t]{2}{*}{ Fan 2001 [20] } & $\mathrm{HR}$ & 74 & 12 & NA & 53.9 & NA & 26.9 & 16.6 \\
\hline & TACE & 18 & 5 & NA & 22.2 & NA & 5.6 & 0 \\
\hline \multirow[t]{2}{*}{ Fan 2003 [19] } & $H R$ & 19 & 10.3 & 45.9 & 14.2 & 0 & 0 & NA \\
\hline & TACE & 41 & 7.1 & 34.2 & 12.2 & 0 & 0 & NA \\
\hline \multirow[t]{2}{*}{ Cheng 2005 [18] } & $H R$ & 7 & $8.0(4.5-11.5)$ & NA & 14.3 & NA & NA & NA \\
\hline & TACE & 38 & $5.0(4.4-5.6)$ & NA & 10.5 & NA & NA & NA \\
\hline \multirow[t]{2}{*}{ Fan 2005 [21] } & $H R$ & 24 & 10.1 & 46.8 & 22.7 & 9.8 & 0 & NA \\
\hline & TACE & 53 & 7.3 & 34.6 & 11.8 & 0 & 0 & NA \\
\hline \multirow[t]{2}{*}{ Zhou 2011 [25] } & $H R$ & 38 & 10 & NA & 47.0 & NA & 22.0 & NA \\
\hline & TACE & 10 & 7 & NA & 20.0 & NA & 0 & NA \\
\hline \multirow[t]{2}{*}{ Peng 2012 [12] } & $H R$ & 201 & $20.0 \pm 1.8$ & NA & 42.0 & NA & 14.1 & 11.1 \\
\hline & TACE & 402 & $13.1 \pm 0.6$ & NA & 37.8 & NA & 7.3 & 0.5 \\
\hline \multirow[t]{2}{*}{ Liu PH 2014 [22] } & $\mathrm{HR}$ & 108 & 64 & NA & 84 & NA & 69 & 69 \\
\hline & TACE & 108 & 32 & NA & 71 & NA & 50 & 35 \\
\hline \multirow[t]{2}{*}{ Liu K 2014 [17] } & $H R$ & 41 & 21.5 & NA & 70.1 & 40.8 & 16.7 & NA \\
\hline & TACE & 72 & 13.8 & NA & 44.8 & 17.4 & 7.5 & NA \\
\hline \multirow[t]{2}{*}{ Ye 2014 [24] } & $H R$ & 90 & 8.2 & NA & 28 & 20 & 15 & NA \\
\hline & TACE & 86 & 7.0 & NA & 17.5 & 0 & 0 & NA \\
\hline \multirow[t]{2}{*}{ Lee 2016 [13] } & $H R$ & 40 & 19.9 & NA & 64.7 & 58.3 & 49.9 & NA \\
\hline & TACE & 80 & 6.6 & NA & 46.2 & 15.4 & 7.7 & NA \\
\hline \multirow[t]{2}{*}{ Zheng 2016 [1] } & $\mathrm{HR}$ & 96 & NA & NA & 86.5 & NA & 60.4 & 33.3 \\
\hline & TACE & 134 & NA & NA & 77.6 & NA & 47.8 & 20.9 \\
\hline \multirow[t]{2}{*}{ Wang 2016 [11] } & $\mathrm{HR}$ & 745 & NA & NA & 49.1 & 29.1 & 18.3 & 9.5 \\
\hline & TACE & 604 & NA & NA & 27.6 & 11.3 & 6.8 & 4.6 \\
\hline
\end{tabular}




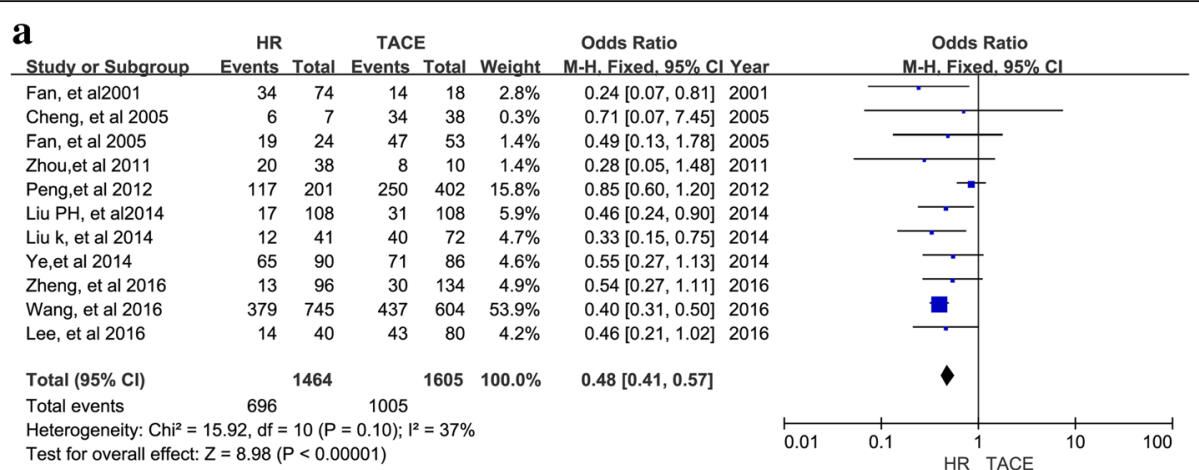

b

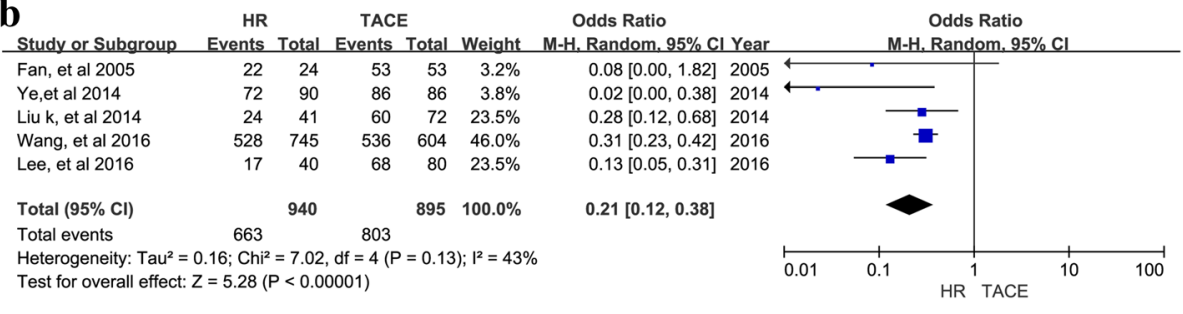

C

HR TACE Odds Ratio

\begin{tabular}{lrrrrrrr} 
Study or Subgroup & Events & Total & \multicolumn{2}{c}{ Events } & Total & Weight & M-H. Fixed, 95\% Cl Year \\
\hline Fan, et al2001 & 54 & 74 & 17 & 18 & $2.6 \%$ & $0.16[0.02,1.27] 2001$
\end{tabular}

$\begin{array}{lllllll}\text { Fan, et al } 2005 & 24 & 24 & 53 & 53 & & \text { Not estimable } 2005\end{array}$

$\begin{array}{llllll}\text { Zhou,et al } 2011 & 30 & 38 & 10 & 10 & 1.3 \%\end{array}$

Peng,et al 2012

Liu PH, et al2014

Ye,et al 2014

Liu k, et al 2014

Lee, et al 2016

Zheng, et al 2016

Wang, et al 2016

$\begin{array}{llllr}173 & 201 & 373 & 402 & 12.4 \%\end{array}$

$\begin{array}{lllll}34 & 41 & 67 & 72 & 3.0 \%\end{array}$

$\begin{array}{lllll}33 & 108 & 54 & 108 & 13.4 \%\end{array}$

$0.17[0.01,3.22] 2011$

$0.36[0.11,1.23] 2014$

$0.44[0.25,0.77] 2014$

$0.03[0.00,0.52] 2014$

$0.60[0.35,1.02] 2016$

$0.60[0.35,1.02] 2016$
$0.08[0.03,0.23] 2016$

$0.08[0.03,0.23] 2016$
$0.33[0.23,0.47] 2016$

Total $(95 \% \mathrm{Cl})$

Total events

$\begin{array}{lllll}38 & 96 & 70 & 134 & 12.7 \%\end{array}$

$\begin{array}{lllll}20 & 40 & 74 & 80 & 8.8 \%\end{array}$

$1091 \quad 1367$

$\mathrm{Chi}^{2}=17.18, \mathrm{df}=8(\mathrm{P}=0.03) ; \mathrm{I}^{2}=53 \%$

Test for overall effect: $Z=9.22(P<0.00001)$

$0.35[0.28,0.44]$

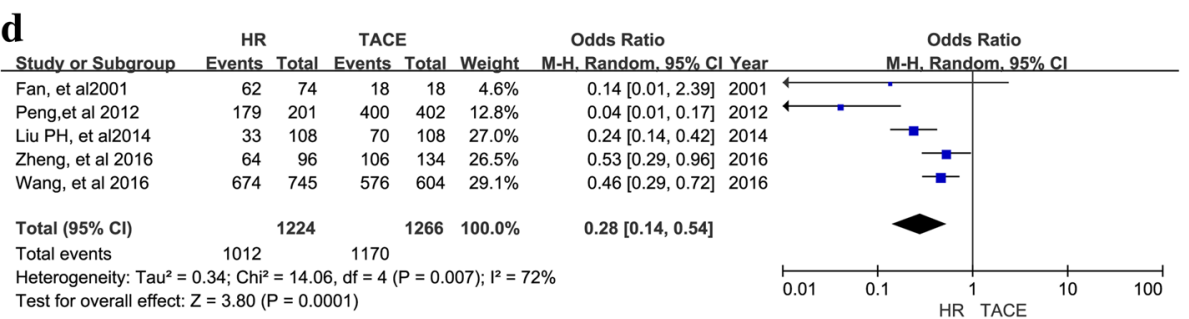

Fig. 2 Forest plots for the comparison of ORs for OS in all included HCC patients with PVTT who received HR or TACE. Outcomes: a 1-year OS; b 2-year OS; c 3-year OS; d 5-year OS; A random effects model was used in the meta-analyses of the three outcomes

tumor thrombus involving the main portal vein trunk; Type IV: tumor thrombus involving the superior mesenteric vein) [26, 27]. As shown in Table 4, 7 of the 12 included studies indicated the OS for different types of PVTT in all patients $[12,13,17,20,23-25]$. Only one article reported OS rates for type IV PVTT at 1, 3, and 5 years in patients undergoing HR; these rates were $21.7 \%, 0 \%$, and $0 \%$, respectively, and were the same as those for patients undergoing TACE (1-year: 30.4\%, 3year: $4.3 \%$, and 5 -year: $0 \%$, respectively; $P=0.371$ ). Based on the data (Table 4) patients with type I and II PVTT in the first-order portal vein branch or lower-order portal vein branches had better results than patients with type III and IV PVTT in the main portal vein or the upper branches to the superior mesenteric vein. Therefore, Zheng et al. suggested that the OS of patients with type I PVTT was comparable to that of patients with type II PVTT $(P>0.05)$; similarly, the OS rates of patients with types III and IV PVTT were comparable $(P>0.05)[11]$.

For type I PVTT, 4 studies reported 1-, 2-, 3-, and 5year OS rates and corresponding ORs and were included in the meta-analysis. As shown in Fig. 3, the ORs for 1-, 2-, 3, 5-year OS for type I PVTT were better following 
Table 4 Outcomes of patients under HR or TACE for various PVTT types

\begin{tabular}{|c|c|c|c|c|c|c|c|c|}
\hline Study(year) & Treatment & Type of PVTT & Patients & Median OS(months) & 1-year(\%) & 2-year(\%) & 3-year(\%) & $\begin{array}{l}5 \text {-year(\%) of } \\
\text { Survival rates }\end{array}$ \\
\hline \multirow[t]{4}{*}{ Fan 2001 [20] } & \multirow[t]{2}{*}{$\mathrm{HR}$} & Type II & 58 & 13.0 & 59.7 & NA & 27.4 & 8.8 \\
\hline & & Type III & 16 & 8.0 & 29.4 & NA & 14.3 & 11.1 \\
\hline & \multirow[t]{2}{*}{ TACE } & Type II & 12 & 5.0 & 16.7 & NA & 8.3 & 0 \\
\hline & & Type III & 6 & 5.5 & 33.3 & NA & 0 & 0 \\
\hline \multirow[t]{8}{*}{ Peng 2012 [12] } & \multirow[t]{4}{*}{$H R$} & Type I & 27 & NA & 81.5 & NA & 51.2 & 37.9 \\
\hline & & Type II & 68 & NA & 46.3 & NA & 17.2 & 17.2 \\
\hline & & Type III & 83 & NA & 32.5 & NA & 3.6 & 3.6 \\
\hline & & Type IV & 23 & NA & 21.7 & NA & 0 & 0 \\
\hline & \multirow[t]{4}{*}{ TACE } & Type I & 64 & NA & 41.1 & NA & 8.9 & 3.6 \\
\hline & & Type II & 136 & NA & 37.9 & NA & 6.0 & 0 \\
\hline & & Type III & 166 & NA & 36.1 & NA & 4.2 & 0 \\
\hline & & Type IV & 46 & NA & 30.4 & NA & 4.3 & 0 \\
\hline \multirow[t]{6}{*}{ Liu K 2014 [17] } & \multirow[t]{3}{*}{$H R$} & Type I & 12 & 30.0 & 100.0 & 66.7 & 30.0 & NA \\
\hline & & Type ॥ & 21 & 18.2 & 66.7 & 32.6 & 0 & NA \\
\hline & & Type III & 8 & 8.9 & 25.0 & 0 & 0 & NA \\
\hline & \multirow[t]{3}{*}{ TACE } & Type I & 24 & 19.7 & 74.8 & 30.8 & 12.8 & NA \\
\hline & & Type II & 32 & 10.8 & 25.9 & 9.7 & 0 & NA \\
\hline & & Type III & 16 & 7.4 & 25.0 & 0 & 0 & NA \\
\hline \multirow[t]{4}{*}{ Lee 2016 [13] } & \multirow[t]{2}{*}{$H R$} & Type I & 16 & NA & 71.4 & 54.5 & 54.4 & NA \\
\hline & & Type II & 8 & NA & 35.0 & 0 & 0 & NA \\
\hline & \multirow[t]{2}{*}{ TACE } & Type I & 12 & NA & 50.0 & 25.0 & 16.7 & NA \\
\hline & & Type ॥ & 14 & NA & 35.7 & 7.1 & 0 & NA \\
\hline \multirow[t]{6}{*}{ Wang 2016 [11] } & \multirow[t]{3}{*}{$\mathrm{HR}$} & Type I & 122 & $14.7(10.7-18.7)$ & 57.2 & 36.1 & 21.0 & 10.0 \\
\hline & & Type ॥ & 187 & $12.1(10.0-14.2)$ & 50.8 & 31.0 & 22.3 & 13.3 \\
\hline & & Type III & 171 & $6.2(4.4-7.9)$ & 36.3 & 17.4 & 8.2 & 2.6 \\
\hline & \multirow[t]{3}{*}{ TACE } & Type I & 45 & $8.7(4.1-13.3)$ & 40.0 & 17.3 & 7.3 & 0 \\
\hline & & Type ॥ & 187 & $5.3(4.4-6.2)$ & 25.1 & 9.5 & 5.3 & 4.5 \\
\hline & & Type III & 171 & $5.2(3.7-6.6)$ & 28.1 & 12.1 & 6.7 & 5.7 \\
\hline
\end{tabular}

$\mathrm{HR}$ than TACE $(\mathrm{OR}=0.33,95 \% \mathrm{CI}=0.17-0.64, \mathrm{I} 2=$ $20 \%, P=0.001$, Fig. 3a; $\mathrm{OR}=0.32,95 \% \mathrm{CI}=0.16-0.63$, $\mathrm{I} 2=0 \%, P=0.001$, Fig. $3 \mathrm{~b}$; and $\mathrm{OR}=0.18,95 \% \mathrm{CI}=$ $0.09-0.36$, I2 $=0 \%, P<0.00001$, Fig. $3 c ;$ OR $=0.07,95 \%$ $\mathrm{CI}=0.01-0.32, \mathrm{I} 2=0 \%, P=0.0006$, Fig. $3 \mathrm{~d})$, respectively). For type II PVTT, 5 studies reported ORs for 1-, 3-, and 5 -year $\mathrm{OS}$ and were included in the meta-analysis, $(\mathrm{OR}=$ $0.37,95 \% \mathrm{CI}=0.20-0.70$, I2 $=59 \%, P=0.002$, Fig. $4 \mathrm{a}$; OR $=0.22,95 \% \mathrm{CI}=0.13-0.39, \mathrm{I} 2=0 \%, P<0.00001$, Fig. $4 \mathrm{~b}$; $\mathrm{OR}=0.16 ; 95 \% \mathrm{CI}=0.03-0.91 ; \mathrm{I} 2=51 \%, P=0.04$, Fig. $4 \mathrm{c}$, respectively). Type I and II PVTT patients had a longer OS following HR than TACE. In contrast, the 1-, 3-, and 5-year OS for patients with type III PVTT were not significantly different following HR versus TACE. Correspondingly, the meta-analysis of ORs for 1-, 3-, and 5-year OS suggested that patients with type III
PVTT can undergo either HR or TACE with similar results $(\mathrm{OR}=0.86,95 \% \mathrm{CI}=0.61-1.21, \mathrm{I} 2=0 \%, \quad P=$ 0.39 , Fig. $5 \mathrm{a}$; $\mathrm{OR}=0.83,95 \% \mathrm{CI}=0.42-1.64, \mathrm{I} 2=0 \%$, $P=0.59$, Fig. 5b; OR $=0.59,95 \% \mathrm{CI}=0.06--6.04, \mathrm{I} 2=$ $65 \%, P=0.66$, Fig. 5 c, respectively).

Univariate and multivariate analyses of OS of PVTT patients Whether potential correlations exist between OS and selected variables has not been reported. Thus, univariate and multivariate analyses of OS were performed for all patients in 7 studies [11-13, 21, 22, $24,25]$. In the univariate analysis, age, gender, BMI, race, cause of liver disease, preoperative antiviral therapy, portal hypertension, tumor size, tumor number, type of PVTT, Child-Pugh class, initial modalities of treatment, number of TACE cycles, AFP level $\geq$ 


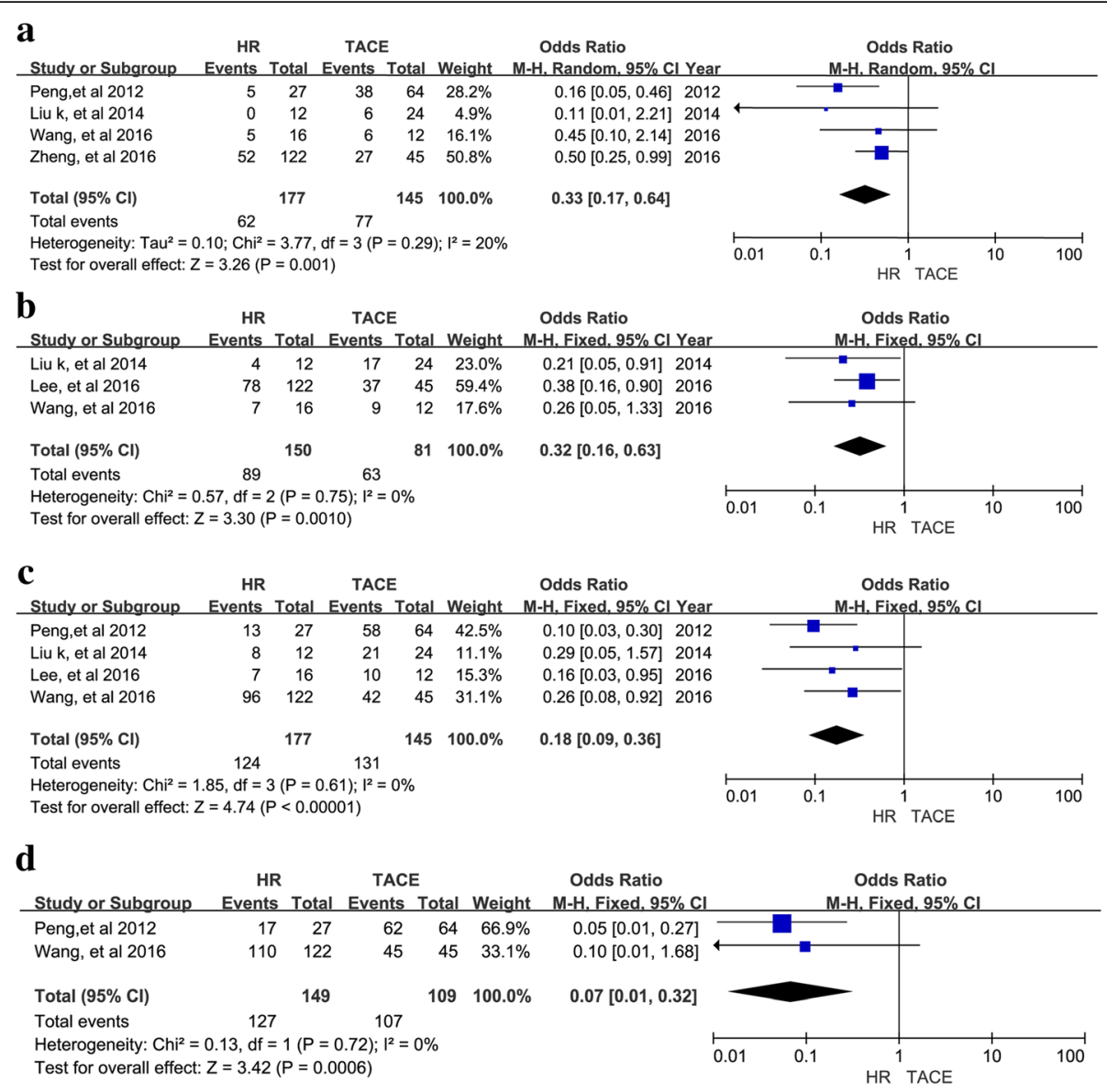

Fig. 3 Forest plots for the comparison of ORs for OS in HCC patients with type I PVTT who received HR or TACE. Outcomes: a 1-year OS; b. 2-year OS; c 3-year OS; d 5-year OS; A random effects model was used in the meta-analyses of the three outcomes

$400 \mathrm{ng} / \mathrm{mL}$, and NLR (neutrophil-lymphocyte ratio) $\geq 4$ were found to predict poor OS across the 7 articles. Multivariate Cox proportional hazards regression analysis of all 7 studies indicated that type of PVTT and initial modalities of treatment may be significant prognostic factors for OS $[12,13]$.

\section{Discussion}

There is a high incidence of PVTT in patients with advanced HCC, which is a significant prognostic factor for OS. Sorafenib is the only recommended treatment for PVTT according to BCLC C stage international guidelines for HCC patients. Recently, comprehensive treatments such HR and TACE $[8,28]$ have become available for HCC patients with PVTT, but use of these options remains controversial. This study is the first systematic review and meta-analysis to compare OS in HCC patients with PVTT receiving TACE or HR and provides a foundation for selecting appropriate clinical treatment. The analysis included 3129 HCC patients with PVTT. The results showed that HR was more effective and led to greater improvements in 1-, 2-, 3-, and 5-year OS for all included PVTT patients compared with TACE. Patients with type I and II PVTT experienced the greatest benefit.

Previous studies have suggested that HR is a safe and effective treatment for HCC with PVTT when patients are carefully selected. As reported in Ye et al. and Wang et al., PVTT patients undergoing HR have significantly higher OS than patients undergoing conservative treatment or TACE [23, 24]. Kokudo T et al. demonstrated that HR is associated with a longer OS than non-surgical treatment for patients with PVTT limited to the firstorder branch [8]. The median survival time in the HR group was 1.77 years longer than that in the non-HR group ( 2.87 years vs 1.10 years; $P<0.001)$ and 0.88 years longer than that in the non-LR group (2.45 years vs 1.57 years; $\mathrm{P}<0.001$ ) in a propensity score-matched cohort. HR can eradicate both a main tumor and satellite tumors as well as PVTT to reduce the pressure on the portal vein, preventing the occurrence of intractable ascites and bleeding of esophageal varices, protecting liver function, and reducing tumor burden as well as intrahepatic and extrahepatic metastasis of HCC [29-31]. Thus, HR 


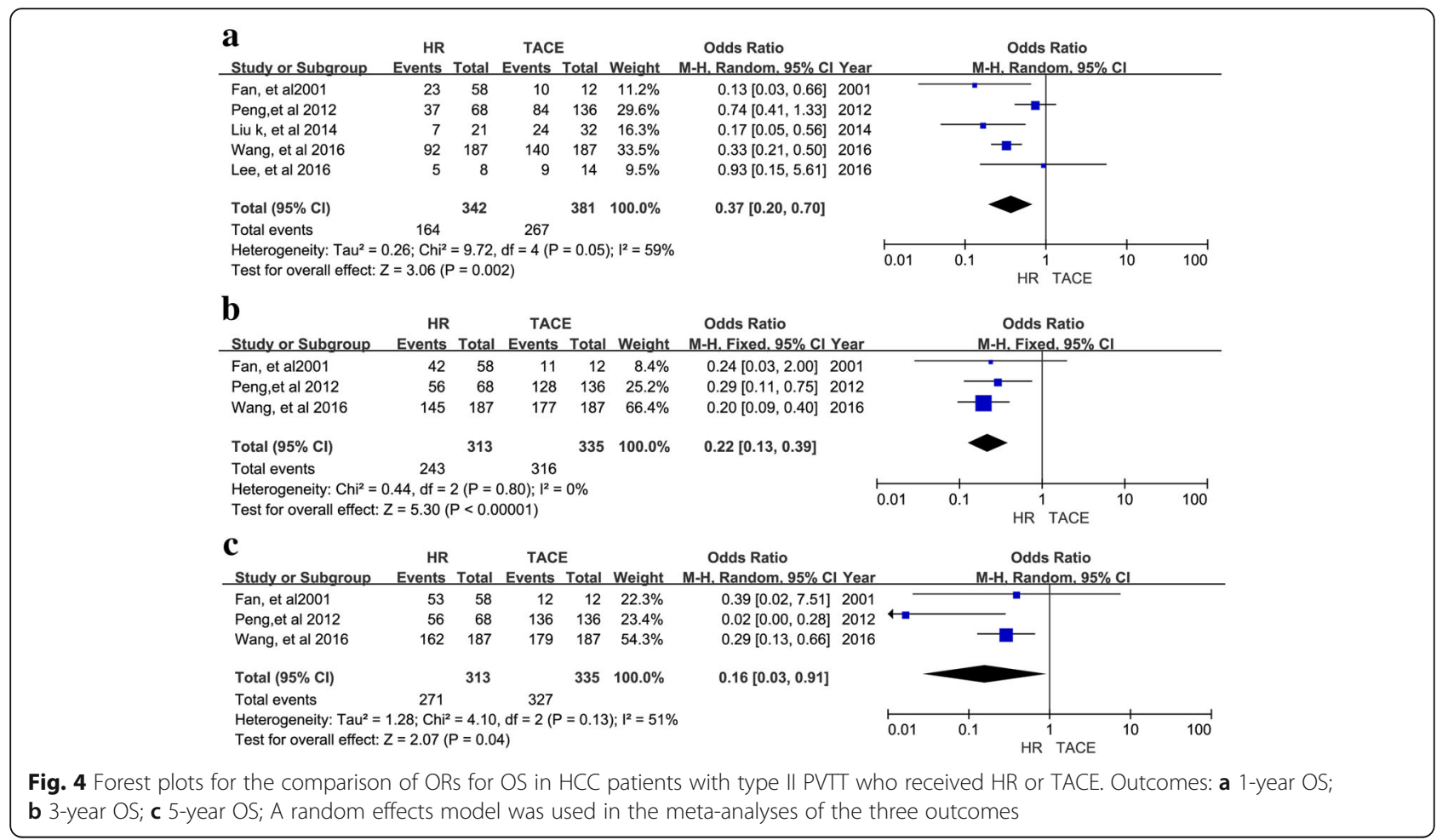

is considered to be potentially curative and is the preferred treatment for HCC patients with PVTT. However, several studies have reported that TACE is effective for the treatment of patients with advanced HCC with PVTT [7, 28, 32]. TACE is used to embolize arteries supplying blood and nutrients to tumors and has been used as adjunctive therapy for advanced HCC with PVTT, especially for preoperative and postoperative treatment [33, 34]. Previous reports have been inconclusive regarding whether HR or TACE has more benefits for PVTT. In this systematic review and meta-

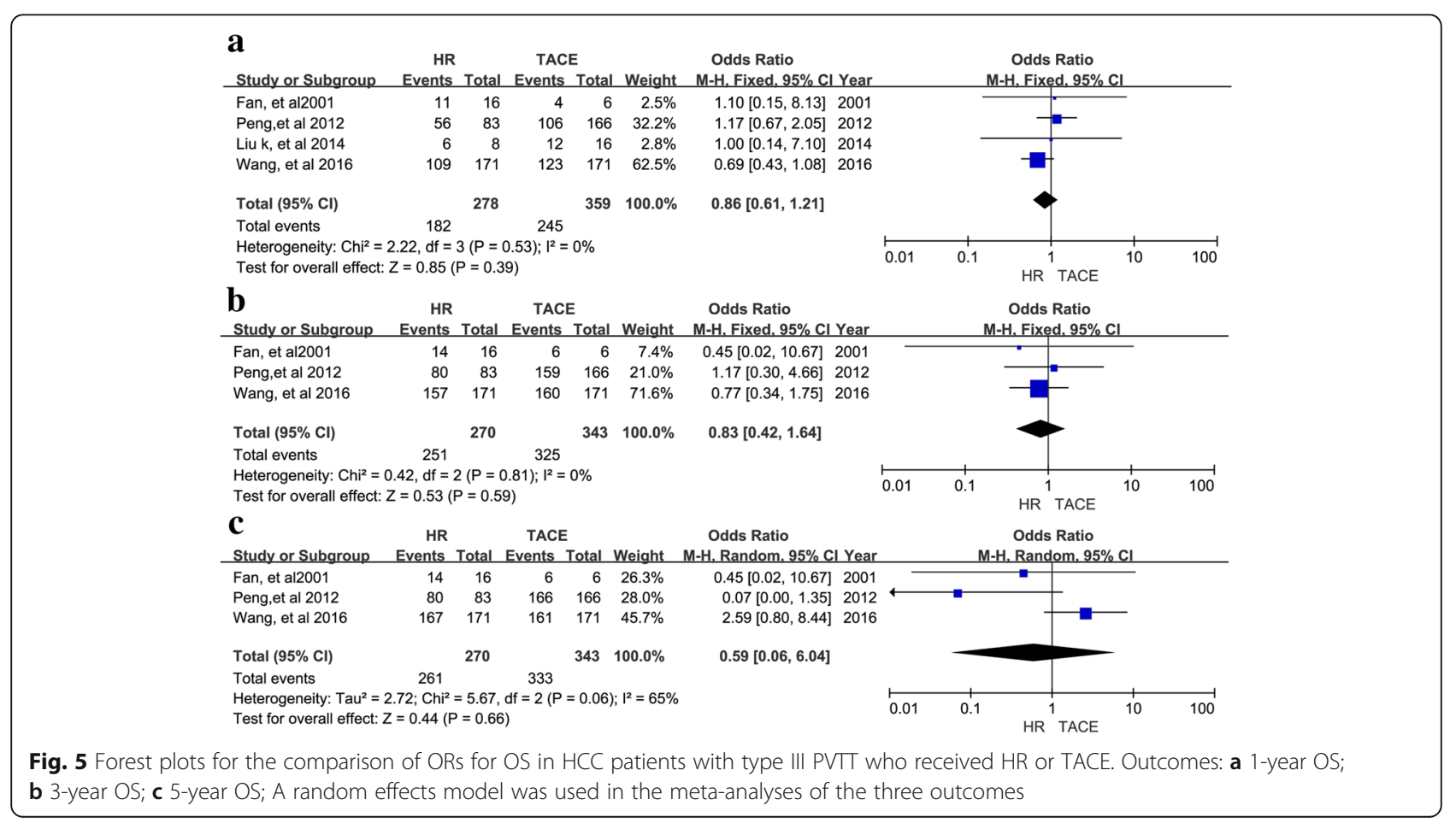


analysis, 1-, 2-, 3-, and 5-year OS showed greater improvements following HR than TACE for all included patients. These results further validated that some selected HCC patients with PVTT who have good liver function and no extrahepatic metastasis should be considered for HR. Notably, patients' prognosis varied depending on PVTT type. Therefore, future studies should further clarify what types of PVTT respond better to HR or TACE.

The therapeutic effects of HR and TACE for various PVTT types were compared via subgroup analyses. For type I PVTT, defined as a tumor thrombus involving the segmental branches of the portal vein or above, the meta-analysis of 1-, 2-, 3, 5-year OS indicated that HR is more the appropriate treatment, producing a longer OS than TACE. Similarly, for patients with type II PVTT, the ORs corresponding to 1-, 3-, and 5-year OS suggested HR leads to better outcomes than TACE. These results agree with a study of a large cohort in Japan [8], wherein HR was associated with a longer OS than nonsurgical treatment, including TACE, chemotherapy or transarterial chemoinfusion, ablation therapy, and bestsupportive care, for patients with PVTT limited to the first-order branch of Vp1-3 [35], namely, those with type I or II PVTT. In the largest sample study conducted in China to date [23], the MST for type I and II patients (95\% CI) undergoing HR was 15.9 (13.3-18.5) and 12.5 (10.7-14.3) months, respectively, while the corresponding figures for patients undergoing TACE were 9.3 (5.6$12.9)$ and $4.9(4.1-5.7)$ months, respectively, which were significantly lower than those after HR $(P<0.05)$. This meta-analysis with high credibility than two respective studies illustrated that HR was the best treatment for type I and II PVTT patients with Child-Pugh A and selected B liver function. However, for type III PVTT, defined as a tumor thrombus involving the main portal vein trunk, this meta-analysis was unable to find differences in 1-, 3-, and 5-year OS between HR and TACE with high reliability. Based on these results, HR and TACE produce similar outcomes when treating patients with type III PVTT $(P=0.541)$. Although these patients can therefore choose either HR or TACE with good outcomes, most cannot receive HR because of PVTT extending to the main portal vein. Type III patients have poor liver function and high portal vein pressure; therefore, a single treatment is typically ineffective. TACE combined with radiotherapy should be given to type III PVTT patients according to Wang et al. [23] Preoperative adjuvant therapy such as TACE and radiotherapy could stage down type III PVTT to type I or II PVTT, which would then allow HR or TACE to be performed to achieve a longer OS [36]. Type IV PVTT, defined as a tumor thrombus involving the superior mesenteric vein, is rarely seen in HCC patients. Type IV PVTT is regarded as late-stage PVTT and corresponds to an extremely short OS. Although the use of HR for type IV PVTT remains controversial [37], Peng et al. [12] reported 1 -, 3-, and 5 -year OS rates of $21.7 \%, 0 \%$, and $0 \%$, respectively, for this treatment modality. However, no significant differences were found between $H R$ and TACE for patients with type IV PVTT $(P=0.371)$. Thus, HR other than TACE should be performed for HCC patients with type I or II PVTT as opposed to those with type III or IV PVTT.

The study has several potential limitations. First, this meta-analysis contained numerous NRCT studies because there were no RCTs examining HR or TACE for the treatment of PVTT; therefore, selection bias was possible. Second there was significant heterogeneity between studies for some outcomes, which could have resulted from the quality of the NRCT studies, the small number of included studies especially in subset analyses, and the patient characteristics. The above limitations could have affected the results of this meta-analysis.

\section{Conclusions}

In conclusion, the current systematic review and metaanalysis suggested that treatment of selected HCC patients with type I or II PVTT with HR may produce superior results to TACE. In contrast, there was no difference between HR and TACE for type III and IV PVTT. It is imperative to design additional rigorous multicenter RCTs with large samples to assess the use of HR and TACE in PVTT patients.

\section{Abbreviations \\ 95\% Cls: 95\% Confidence intervals; BCLC: Barcelona clinic liver cancer; HCC: Hepatocellular carcinoma; HR: Hepatic resection; HRs: Hazard ratios; MST: Median survival time; NRCT: Nonrandomized Controlled Trials; ORs: Odds ratios; OS: Overall survival; PVTT: Portal vein tumor thrombus; RCT: Randomized controlled trials; TACE: Transarterial chemoembolization}

\section{Acknowledgements}

Not applicable.

\section{Funding}

Study design: The National Key Basic Research Program "973 project" (No: 2015CB554000); the Science Fund for Creative Research Groups (No: 81,521,091); the China National Funds for Distinguished Young Scientists (No: 81,125,018); the ChangJiang Scholars Program (2013) of the Chinese Ministry of Education; Data collection and analysis: The Shanghai Science and Technology Committee (No: 134119a0200, SHDC12015106); the National Natural Science Foundation of China (No: 8,160,110,271);

Manuscript drafting and revision: The SMMU Innovation Alliance for Liver Cancer Diagnosis and Treatment (2012).

\section{Availability of data and materials}

The datasets generated and analyzed during the current study are not publicly available because further fundamental and clinical research will be carried out based on this cohort; however, they are available from the corresponding author upon reasonable request.

\section{Authors' contributions}

$X P Z, K W$ and NL: contributed equally to this article, collected and analyzed data, drafted and revised the manuscript. CQZ, XBW and YQC: collected and analyzed data. YZG and HW: collected data, revised the manuscript. SQC: 
designed the study, collected data, revised the manuscript. All authors read and approved the final manuscript.

\section{Ethics approval and consent to participate}

The study was approved by the Institutional Review Board of Eastern Hepatobiliary Surgery Hospital, and written informed consent was obtained from all patients for their data to be used in this research.

\section{Consent for publication}

Not applicable.

\section{Competing interests}

The authors who have taken part in this study declared that they do not have anything to disclose regarding funding or conflict of interest with respect to this manuscript.

\section{Publisher's Note}

Springer Nature remains neutral with regard to jurisdictional claims in published maps and institutional affiliations.

\section{Author details}

'Department of Hepatic Surgery VI, Eastern Hepatobiliary Surgery Hospital, Second Military Medical University, 225 Changhai Road, Shanghai 200433, China. ${ }^{2}$ Department of Laboratory Medicine, Eastern Hepatobiliary Surgery Hospital, Second Military Medical University, Shanghai, China. ${ }^{3}$ Department of Pathology, Eastern Hepatobiliary Surgery Hospital, Second Military Medical University, Shanghai, China.

Received: 21 April 2017 Accepted: 8 December 2017

Published online: 28 December 2017

\section{References}

1. Chen W, Zheng R, Baade PD, Zhang S, Zeng H, Bray F, Jemal A, Yu XQ, He J. Cancer statistics in China, 2015. CA Cancer J Clin. 2016;66(2):115-32.

2. Llovet JM, Bustamante J, Castells A, Vilana R, Ayuso Mdel C, Sala M, Bru C, Rodes J, Bruix J. Natural history of untreated nonsurgical hepatocellular carcinoma: rationale for the design and evaluation of therapeutic trials. Hepatology. 1999;29(1):62-7.

3. Bruix J, Raoul JL, Sherman M, Mazzaferro V, Bolondi L, Craxi A, Galle PR, Santoro A, Beaugrand M, Sangiovanni A, et al. Efficacy and safety of sorafenib in patients with advanced hepatocellular carcinoma: subanalyses of a phase III trial. J Hepatol. 2012;57(4):821-9.

4. Llovet JM, Ricci S, Mazzaferro V, Hilgard P, Gane E, Blanc JF, de Oliveira AC, Santoro A, Raoul JL, Forner A, et al. Sorafenib in advanced hepatocellular carcinoma. N Engl J Med. 2008;359(4):378-90.

5. Chok KS, Cheung TT, Chan SC, Poon RT, Fan ST, Lo CM. Surgical outcomes in hepatocellular carcinoma patients with portal vein tumor thrombosis. World J Surg. 2014:38(2):490-6.

6. Shaohua L, Qiaoxuan W, Peng S, Qing L, Zhongyuan Y, Ming S, Wei W, Rongping G. Surgical strategy for hepatocellular carcinoma patients with portal/hepatic vein tumor thrombosis. PLoS One. 2015;10(6):e0130021.

7. Leng JJ, Xu YZ, Dong JH. Efficacy of transarterial chemoembolization for hepatocellular carcinoma with portal vein thrombosis: a meta-analysis. ANZ J Surg. 2016;86(10):816-20.

8. Kokudo T, Hasegawa K, Matsuyama Y, Takayama T, Izumi N, Kadoya M, Kudo M, Ku Y, Sakamoto M, Nakashima O, et al. Survival benefit of liver resection for hepatocellular carcinoma associated with portal vein invasion. J Hepatol. 2016;65(5):938-43.

9. Kokudo T, Hasegawa K, Yamamoto S, Shindoh J, Takemura N, Aoki T, Sakamoto Y, Makuuchi M, Sugawara Y, Kokudo N. Surgical treatment of hepatocellular carcinoma associated with hepatic vein tumor thrombosis. J Hepatol. 2014;61(3):583-8.

10. Zhao Y, Duran R, Chapiro J, Sohn JH, Sahu S, Fleckenstein F, Smolka S, Pawlik TM, Schernthaner R, Zhao L, et al. Transarterial chemoembolization for the treatment of advanced-stage hepatocellular carcinoma. J Gastrointest Surg. 2016;20(12):2002-9.

11. Zheng N, Wei X, Zhang D, Chai W, Che M, Wang J, Du B. Hepatic resection or transarterial chemoembolization for hepatocellular carcinoma with portal vein tumor thrombus. Medicine. 2016;95(26):e3959.

12. Peng ZW, Guo RP, Zhang YJ, Lin XJ, Chen MS, Lau WY. Hepatic resection versus transcatheter arterial chemoembolization for the treatment of hepatocellular carcinoma with portal vein tumor thrombus. Cancer. 2012; 118(19):4725-36.

13. Lee JM, Jang BK, Lee YJ, Choi WY, Choi SM, Chung WJ, Hwang JS, Kang KJ, Kim $\mathrm{YH}$, Chauhan AK, et al. Survival outcomes of hepatic resection compared with transarterial chemoembolization or sorafenib for hepatocellular carcinoma with portal vein tumor thrombosis. Clin Mol Hepatol. 2016;22(1):160-7.

14. Moher D, Liberati A, Tetzlaff J, Altman DG, Group P. Preferred reporting items for systematic reviews and meta-analyses: the PRISMA statement. BMJ. 2009;339:b2535.

15. Sutton AJ, Duval SJ, Tweedie RL, Abrams KR, Jones DR. Empirical assessment of effect of publication bias on meta-analyses. BMJ. 2000;320(7249):1574-7.

16. Higgins JP, Thompson SG, Deeks JJ, Altman DG. Measuring inconsistency in meta-analyses. BMJ. 2003:327(7414):557-60.

17. Liu K, Wu XF, Yang Q, Wei XB, Xiang BD, Wu GB, et al. Comparison of surgical resection versus transarterial chemoembolization in single hepatocellular carcinoma with portal vein tumor thrombosis patinets. J Guangxi Med Univ. 2014:31(2):216-9.

18. Cheng SQ, Wu MC, Chen H, Shen F, Yang JH, Cong WM, et al. Hepatocellular carcinoma with tumor thrombi in the portal vein: a comparison of therapeutic effects by different tratments. Chin J Oncol. 2005;27(3):183-5.

19. Fan J, Wu ZQ, Zhou J, Qiu SJ, Chen RX, Shi YH. Comparison of the results and therapies for hepatocellular carcinoma with tumor thrombosis in portal vein. Chin J Surg. 2003;41(11):801-4

20. Fan J, Wu ZQ, Tang ZY, Zhou J, Qiu SJ, Ma ZC, Zhou XD, Ye SL. Multimodality treatment in hepatocellular carcinoma patients with tumor thrombi in portal vein. World J Gastroenterol. 2001;7(1):28-32.

21. Fan J, Zhou J, Wu ZQ, Qiu SJ, Wang XY, Shi YH, Tang ZY. Efficacy of different treatment strategies for hepatocellular carcinoma with portal vein tumor thrombosis. World J Gastroenterol. 2005:11(8):1215-9.

22. Liu PH, Lee YH, Hsia CY, Hsu CY, Huang YH, Chiou YY, Lin HC, Huo TI. Surgical resection versus transarterial chemoembolization for hepatocellular carcinoma with portal vein tumor thrombosis: a propensity score analysis. Ann Surg Oncol. 2014:21(6):1825-33.

23. Wang K, Guo WX, Chen MS, Mao YL, Sun BC, Shi J, Zhang YJ, Meng Y, Yang YF, Cong WM, et al. Multimodality treatment for Hepatocellular carcinoma with portal vein tumor thrombus: a large-scale, multicenter, propensity Mathching score analysis. Medicine. 2016:95(11):e3015.

24. Ye JZ, Zhang YQ, Ye HH, Bai T, Ma L, Xiang BD, Li LQ. Appropriate treatment strategies improve survival of hepatocellular carcinoma patients with portal vein tumor thrombus. World J Gastroenterol. 2014;20(45):17141-7.

25. Zhou Q, Wang Y, Zhou X, Peng B, Yang J, Liang L, Li J. Prognostic analysis for treatment modalities in hepatocellular carcinomas with portal vein tumor thrombi. Asian Pac J Cancer Prev. 2011;12(11):2847-50.

26. Shuqun C, Mengchao W, Han C, Feng S, Jiahe Y, Guanghui D, Wenming C, Peijun W, Yuxiang Z. Tumor thrombus types influence the prognosis of hepatocellular carcinoma with the tumor thrombi in the portal vein. Hepato-Gastroenterology. 2007:54(74):499-502.

27. Shi J, Lai EC, Li N, Guo WX, Xue J, Lau WY, Wu MC, Cheng SO. A new classification for hepatocellular carcinoma with portal vein tumor thrombus. Hepatobiliary Pancreat Sci. 2011:18(1):74-80.

28. Liu L, Zhang C, Zhao Y, Qi X, Chen H, Bai W, He C, Guo W, Yin Z, Fan D, et al. Transarterial chemoembolization for the treatment of advanced hepatocellular carcinoma with portal vein tumor thrombosis: prognostic factors in a singlecenter study of 188 patients. Biomed Res Int. 2014:2014:194278.

29. Arii S, Tanaka S, Mitsunori Y, Nakamura N, Kudo A, Noguchi N, Irie T. Surgica strategies for hepatocellular carcinoma with special reference to anatomical hepatic resection and intraoperative contrast-enhanced ultrasonography. Oncology. 2010;78(Suppl 1):125-30.

30. Shi J, Lai EC, Li N, Guo WX, Xue J, Lau WY, Wu MC, Cheng SQ. Surgical treatment of hepatocellular carcinoma with portal vein tumor thrombus. Ann Surg Oncol. 2010;17(8):2073-80.

31. Xu JF, Liu XY, Wang S, Wen HX. Surgical treatment for hepatocellular carcinoma with portal vein tumor thrombus: a novel classification. World J Surg Oncol. 2015;13:86.

32. Tawada A, Chiba T, Ooka Y, Kanogawa N, Motoyama T, Saito T, Ogasawara S, Suzuki E, Maruyama H, Kanai F, et al. Efficacy of transarterial chemoembolization targeting portal vein tumor thrombus in patients with hepatocellular carcinoma. Anticancer Res. 2014;34(8):4231-7.

33. Bai T, Chen J, Xie ZB, Wu FX, Wang SD, Liu JJ, Li LQ. The efficacy and safety of postoperative adjuvant transarterial embolization and radiotherapy in 
hepatocellular carcinoma patients with portal vein tumor thrombus. OncoTargets Ther. 2016;9:3841-8.

34. Zhang YF, Guo RP, Zou RH, Shen JX, Wei W, Li SH, OuYang HY, Zhu HB, Xu L, Lao XM, et al. Efficacy and safety of preoperative chemoembolization for resectable hepatocellular carcinoma with portal vein invasion: a prospective comparative study. Eur Radiol. 2016;26(7):2078-88.

35. Kudo M, Izumi N, Kokudo N, Matsui O, Sakamoto M, Nakashima O, Kojiro M, Makuuchi M, Hepatology HCCEPoJSo. Management of hepatocellular carcinoma in Japan: consensus-based clinical practice guidelines proposed by the Japan Society of Hepatology (JSH) 2010 updated version. Dig Dis. 2011;29(3):339-64.

36. Cheng $\mathrm{S}$, Chen M, Cai J. National Research Cooperative Group for Diagnosis and Treatment of Hepatocellular Carcinoma with Tumor Thrombus. Chinese expert consensus on multidisciplinary diagnosis and treatment of hepatocellular carcinoma with portal vein tumor thrombus: 2016 edition. Oncotarget. 2017;8(5):8867-76.

37. Chen XP, Qiu FZ, Wu ZD, Zhang ZW, Huang ZY, Chen YF, Zhang BX, He SQ, Zhang WG. Effects of location and extension of portal vein tumor thrombus on long-term outcomes of surgical treatment for hepatocellular carcinoma. Ann Surg Oncol. 2006;13(7):940-6.

\section{Submit your next manuscript to BioMed Central} and we will help you at every step:

- We accept pre-submission inquiries

- Our selector tool helps you to find the most relevant journal

- We provide round the clock customer support

- Convenient online submission

- Thorough peer review

- Inclusion in PubMed and all major indexing services

- Maximum visibility for your research

Submit your manuscript at www.biomedcentral.com/submit 